\title{
Ductile fracture modeling of metallic materials: a short review
}

\author{
Riccardo Fincato, Seiichiro Tsutsumi \\ University of Osaka, JWRI, Japan \\ fincato@jwri.osaka-u.ac.jp, http:/ /orcid.org/0000-0003-4058-0460 \\ tsutsumi@jwri.osaka-u.ac.jp, bttp://orcid.org/0000-0002-9279-0657
}

\begin{abstract}
Since the end of the last century a lot of research on ductile damage and fracture process has been carried out. The interest and the attention on the topic are due to several aspects. The margin to reduce the costs of production or maintenance can be still improved by a better knowledge of the ductile failure, leading to the necessity to overcome traditional approaches. New materials or technologies introduced in the industrial market require new strategies and approaches to model the metal behavior. In particular, the increase of the computational power together with the use of finite elements (FE), extended finite elements (X-FE), discrete elements (DE) methods need the formulation of constitutive models capable of describing accurately the physical phenomenon of the damaging process. Therefore, the recent development of novel constitutive models and damage criteria. This work offers an overview on the current state of the art in nonlinear deformation and damaging process reviewing the main constitutive models and their numerical applications.
\end{abstract}

KEYWORDS. Ductile damage; Finite element method; Experimental characterization; Numerical modeling.

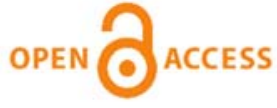

Citation: Fincato, R., Tsutsumi, S., Ductile fracture modelling of metallic materials: a short review, Frattura ed Integrità Strutturale, 59 (2022) 1-17.

Received: 04.10 .2021

Accepted: 09.10.2021

Published: 01.01.2022

Copyright: (C) 2022 This is an open access article under the terms of the CC-BY 4.0, which permits unrestricted use, distribution, and reproduction in any medium, provided the original author and source are credited.

\section{INTRODUCTION}

$\mathrm{T}$ he generation of large inelastic deformations accompanied by the progressive degradation of mechanical properties, and finally by the material failure, is a relevant topic in many competitive industrial sectors (automotive, construction, naval, etc.). An underestimation of the material capability of bearing loads, or an incorrect design of components can lead to a catastrophic outcome with severe consequences in terms of lives or economic impact.

The understanding of the damaging process has a key role under several aspects. Firstly, the prediction of the failure mechanism can lead to a better design of components and structure, with a consistent reduction in the costs production and, more importantly, in maintenance costs. It can help the development and use of new materials and technologies, especially in applications linked to emerging industrial sectors such as biomedical, robotics, and aerospace. Lastly, recent experimental investigations on non-linear deformations and rapture under various loading/boundary conditions provide useful information for the development of constitutive models or empirical formulas for the description of the damage processes. 
In particular, the increase of the computational power incentivized the theoretical research on mechanical models on ductile damage thanks to their implementation in in-house or commercial software based on the finite element (FE) or discrete elements (DE) methods. The great interest around numerical simulations derives from the possibility of conducting parametric studies on components, varying geometrical features, or loading conditions without additional experimental costs. Numerical codes can be applied for the simulation of the service life of large structures such as bridges, skyscrapers, ships, for which full-scale experimental approaches would be unfeasible or too costly. Moreover, experimental campaigns on cyclic loading or low cycle fatigue (LCF) problems can require a considerable time, especially if the investigations are applied to several specimens. FE or DE simulations can speed up the computation process and can be applied on several problems [1-4].

The continuous development of robust damage and fracture models represented, and still represents, an essential point to obtain a more realistic description of the material behavior. On the other hand, since the pioneering works on ductile damage in the second half of the last century, several researchers developed alternative theories for the description of the phenomenon. The present work aims to offer an overview on the current state of the art, pointing out the different aspects that characterize the main constitutive models. The reader should keep in mind that a detailed description of all the existing models is unrealistic since the literature on the topic is quite vast. For the same reason the authors did not report the constitutive equations of the models discussed, the reader is referred to the referenced literature for a in depth description of single theories. The paper is organized as follows. Initially, a brief introduction deals with the definition of the nature of the damage. The experimental characterization of the damaging process is discussed, describing some of the current measuring techniques. Subsequently, an overview of the available models for the damage description, and a discussion of the main aspects of each theory, is offered together with references of recent applications. Finally, some computational aspects are presented.

\section{DAMAGE DEFINITIONS}

$\mathrm{B}$ efore dealing with the experimental characterization and the numerical modeling of the damage phenomenon it is necessary to point out some different mechanisms that lead to the formation of macro cracks.

In fact, even if the outcome of the process is the material failure, the causes for initiation and the evolution of the phenomena are quite different depending on the loading and boundary conditions. Here, a brief description of the fracture processes is given, the reader is referred to [5,6] for an in-depth discussion. In summary, fracture can be distinguished in three mechanisms:

- Ductile fracture. This type of fracture is accompanied by a large amount of irreversible deformations that alter the geometry or shape of the components (i.e. necking, shear bands, etc.). The process is generally triggered by the presence of internal material defects (voids, inclusions) around which a stress localization induces crystallographic slips and the progressive decohesion at the interface between the inclusion and the matrix. Alternatively, the inclusion can break under the effect of the surrounding stress fields. Ductile fracture is characterized by internal micro-cracks formation, driven by high stress triaxialities (see Fig. 1a). The progressive application of the load increases the number and volume of voids and decohesion around defects until their coalescence into a macroscopic crack that quickly propagates until the material failure. In case of low stress triaxiality three failure mechanisms can be observed. In the first, the void nucleation tends to take place in a shear band (see Fig. 1b). The subsequent elongation of the voids induced by shear strain leads to their coalescence and finally to the macroscopic rapture. The second one is named 'void sheeting' where the void nucleation takes place in multiple shear plane that coalesce under shear straining (see Fig. 1c). Finally, the socalled Orowan alternating slip mechanism (OAS). The void nucleation and subsequent coalescence takes place into two intersecting shear bands forming a prismatic cavity at the core of the material (see Fig. 1d). An exhaustive explanation of the different mechanisms is offered in [7]. Ductile rapture is typical of loading conditions that induce a non-negligible amount of plastic deformations, including cyclic mobility and low cycle fatigue (LCF) problems [8-10].

- Low Ductility fracture (often referred as brittle fracture). The type of fracture that belongs to this category is characterized by the formation of cavities between grain boundaries. The cause for these micro-cracks formation can be due to accumulation of dislocation, low melting-point impurity phases or concentration of impurity elements (e.g. $\mathrm{V}$-group elements in steels, $\mathrm{Bi}$ and $\mathrm{Pb}$ in coppers). In particular the presence of impurities is known to promote embrittlement [11,12]. The number and size of cavities increase under the effect of the load on the structure or component and the effect of the temperature. The coalescence of the cavities leads to break some grain boundaries, causing a brittle fracture which can propagates or influence the macro-crack formation and material failure (see Fig. 
2). Detailed information and few examples on numerical modeling of the low ductility fracture can be found in [1315].

- Progressive fracture mechanisms (fatigue or creep). In case of fatigue mechanism, it has to be excluded the scenario where the metallic material fails under cyclic loading conditions after the generation of large plastic deformation (for instance in very low/ low cycle fatigue). In fact, in this case, the fracture mechanism belongs to the aforementioned ductile fracture. Fatigue fracture is characterized by three stages. Firstly, the crack nucleation takes place in persistent slip bands, close or at the free surface, with an inclination of $45^{\circ}$ compared to the loading direction, along the crystallographic slip planes [16]. During the second stage the crack propagates along a plane, more or less, perpendicular to the pulling direction up to a point that the cross section cannot withstand the applied cyclic loading (see Fig. 3). Finally, the third stage consists in the ultimate crack propagation the rate of which is roughly half of the speed of sound in the material [17]. Recent works on fatigue fracture with some numerical applications can be found in [18-22]. Creep fracture is particularly relevant in components that operate at high temperatures (e.g., turbine, petrochemical or nuclear plants, etc.). In this case, creep progressively developed from nucleated intergranular void depending on the loading and heating conditions in the form of irreversible deformations. The evolution of plastic deformation is associated with the enlargement of the voids and their coalescence following three stages: primary, secondary and tertiary creep. After an initial increase of the creep rate during the primary stage a constant creep rate is reached and is kept throughout the second stage. During the tertiary creep a consistent increase of the creep rate is registered until failure. Few works on the topic of creep fracture are reported in [23-28].

The present paper focuses the attention in reviewing the first fracture process. In the following sections we will refer to a damage variable associated with the ductile fracture mechanism. In particular, it is important to point out that the characteristics that define the damage are substantially different from the ones proper of the deformation process. Damage itself consists in the rapture of bonds (atomic bonds between the matrix and defects, atomic bonds between atoms of the defects or the matrix), while elastic deformations are reversible variations of the atomic distances and plastic deformations account for the accumulation or movements of dislocations. Therefore, a new variable must be introduced to describe the damaging process, in addition to the standard variables (i.e., stress, elastic strain, plastic strain, etc.). This aspect will be discussed from a theoretical in the following section 'theoretical damage characterization'. In the next section a more practical approach is introduced, giving some information about the experimental characterization of the damaging process.
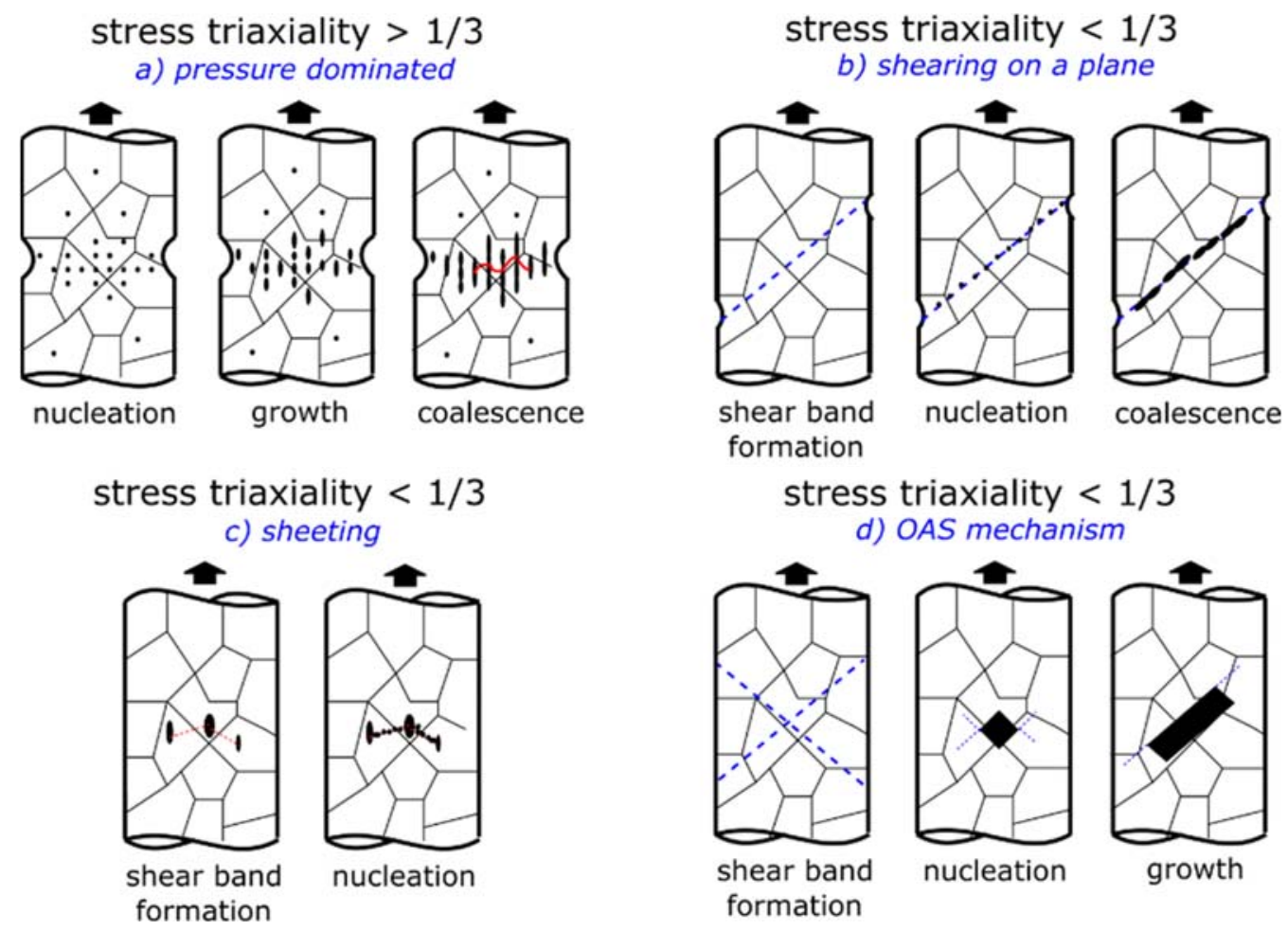

Figure 1: Typical ductile fracture mechanism (simplified and redrawn version of Fig. 2 in [7]). 


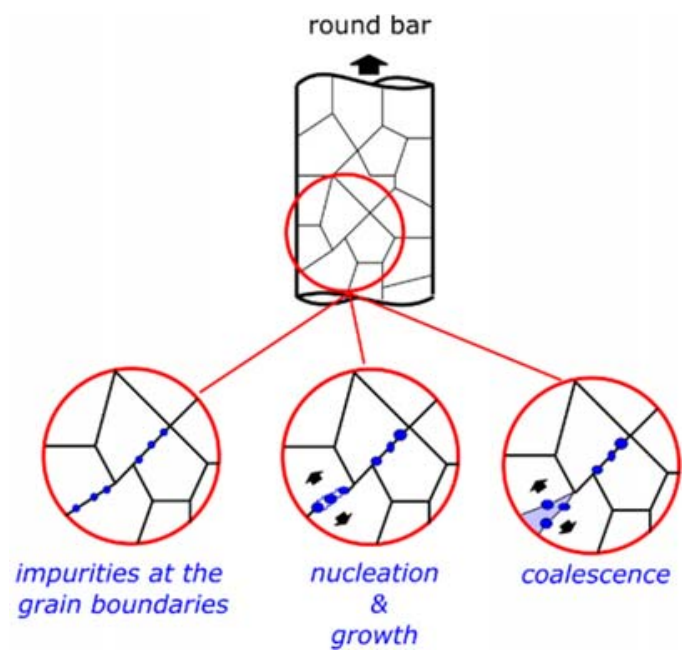

Figure 2: Typical low ductility fracture.

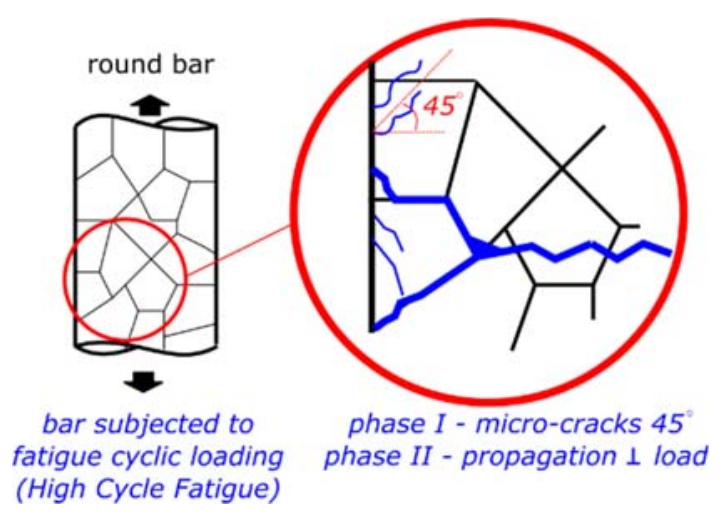

Figure 3: Typical fatigue fracture.

\section{EXPERIMENTAL DAMAGE CHARACTERIZATION}

$\mathrm{T}$ he measurement of the ductile damage in the ongoing of an experiment is a challenging aspect since the damage variable can hardly be measured directly such as other variables (i.e., total force, displacements, strain, geometrical variations, etc.). As mentioned before the damage variable gives an indication about the void formation and growth during the loading and, therefore, it is intrinsically associated with the development of internal cracks.

Currently, there are several techniques that allow a more or less accurate measurement of the damage evolution. A very simple, however time-consuming technique, consists in cutting part of the sample to have a direct observation of the state of void formation. As it can be imagined, the damage evolution can be estimated by a series of tests, performed under the same conditions, where the cut and void observation is done at predefined stages of the loading sequence.

A valid alternative is represented by hardness evaluation by means of indentation. This method consists in recording, throughout the experiment, the magnitude of the applied load and the indentation depth. By the technique proposed by Oliver and Pharr [29], the indentation measure can be correlated to the decrease of the elastic modulus and therefore to the measure of the damage evolution. This expedient can return very accurate values of the local damage and it can be used to evaluate the degradation in strain localization areas (i.e. necking, shear bands, etc.) [30,31].

The electrical resistance of the material can also be used to evaluate the resisting area and therefore to measure the level of damage in the material. The changes in electrical resistance measured during the material loading are mainly due to the generation of plastic deformations and damage. As shown in [30], it is possible to obtain a formula that relates the change in resistance with the evolution of the damage. The damage evaluation seems to be quite good and able to predict a realistic evolution. This last method was proposed by Lemaitre and Dufally [32] and used for the first time by Kumar et al. [33]. 
Micrographic SEM pictures were mentioned by Lemaitre and Dufally [32] as a method to obtain the damage by the comparison of the area fraction that corresponds to voids to the total area observed. SEM picture can be used a posteriori to investigate the nature of the rapture (brittle, ductile, fatigue) [34] giving high resolution images of the damaged area. A recent work by Hutiu et al. [35] proposed the use of optical coherence tomography (OTC) to perform fracture analyses as a valid alternative to SEM pictures. Even though the images obtained with the OTC method are characterized by a much lower resolution of the SEM, the OTC low costs and portability of the equipment make this approach particularly suitable for in situ investigations.

Recently transmission electron microscopy (TEM) has been used to investigate the deformation and fracture mechanisms of materials [36-38]. Thanks to the high-resolution and real-time imaging of this technique it was possible to observe several micro-scale and atomic-scale phenomena leading to the material failure (e.g., dislocation-dominated, twinning-dominated, mechanical annealing, phase transformation). Zhang et al. [39] proposed a methodology that adopts a microelectromechanical systems-based thermomechanical testing apparatus that enabled to observe the atomic-scale ductile mechanism in single crystal tungsten at high temperatures. This type of material is characterized by a brittle type of fracture at room temperature, but the failure mechanism shifts to ductile fracture with the increase of the temperature. The development of a custom-designed transmission electron microscope showed direct evidence of strain induced phase transformation at the crack tip that prevents the brittle fracture improving the ductility.

X-ray micro-tomography can be also used to obtain the volume of the void [40]. One of the advantages of the use of the micro-tomography is the possibility to monitor the whole process from the micro-cracks formation, their growth, coalescence and final macro crack formation. In particular, several authors recurred to this technique for the estimation of the material parameters in numerical simulations. On the other side, micro-tomography requires specialized technicians for its application and it is characterized by high costs compared to other strategies [41-43].

Another technique, often referred in the literature as ultrasonic testing (UT) technique, consists in observing the response of the material to ultrasonic pulses, in order to evaluate the density of voids and internal defects. The difference of the ultrasonic pulse velocity of the sample before and during the experiment can be correlated to the damage evolution [44]. An interesting work by Chiantoni et al. [45] provides an interesting comparison between the micro-tomography and the UT methods for the assessment of the damage evolution in P91 steel at high temperature. It is concluded that both techniques are in good agreement in catching the damage evolution. However, micro-tomography can offer detailed pictures of the actual distribution of voids in the damage localized area, while UT gives an overall evolution of the damage variable in the sample. The lack of resolution of the UT is somehow compensated by the low costs and easy use of the ultrasonic equipment.

The most common technique for the evaluation of the damage is the stiffness or elastic modulus reduction measurement as largely developed and adopted by Lemaitre and Dufally [32] and Bonora et al. [46]. Its application is quite simple, and it consists of a series of measurements of the effective elastic modulus during partial unloading of the sample. The decrease of the modulus can be associated with the progressive loss in the load-carrying capacity of the material caused by the void formation. This technique is quite easy to actuate, and it does not require the use of sophisticated equipment (i.e., SEM pictures, X-ray micro-tomography, ultrasonic pulse).

\section{THEORETICAL DAMAGE CHARACTERIZATION}

\section{Damage preliminaries and characterization of the stress state}

o describe the process that leads to the progressive degradation of the mechanical properties, it is important to understand the factors that influence the nucleation, growth, and coalescence of micro-voids in metallic materials.

Firstly, it is worth mentioning that the growth of the cavities, defects, decohesion inside the material tends to be oriented by the macroscopic load that created them. This means that the variable that should be selected for the description of the process should have a tensorial nature (first, second or even fourth order tensors) or, at least, it should be able to take into account the shape and the orientations of the voids. However, for metallic materials, and in most of industrial applications, the adoption of an isotropic scalar variable can give satisfactory results. For sake of completeness, the reader is referred to $[47,48]$ for examples of tensorial damage variables.

Usually, the process discussed in the 'ductile fracture' bullet point of the previous section can be described by the addition of one, or more, internal variables in elastoplastic constitutive theories. This new variable, or variables, are responsible for describing the formation and progression of cracks until the complete failure of the material. Although the material degradation description depends on the selected constitutive model, a common aspect among several approaches is to 
consider a variable (or variables) limited between two extremes (a scalar variable is assumed in Eq. (1) and generically indicated with $D)$ :

$$
\begin{aligned}
& D=0 \quad \text { non-damaged material } \\
& D=1 \quad \text { material failure }
\end{aligned}
$$

A $D=0$ condition implies an undamaged material, without voids. A $D=1$ condition characterizes the material failure. Often, in finite element analyses, a threshold value $D_{c}<1$ is used (e.g., [49-51]) to indicate the formation of a crack, or the material failure, in order to avoid numerical problems such as damage localization or convergence issues. These aspects are discussed later.

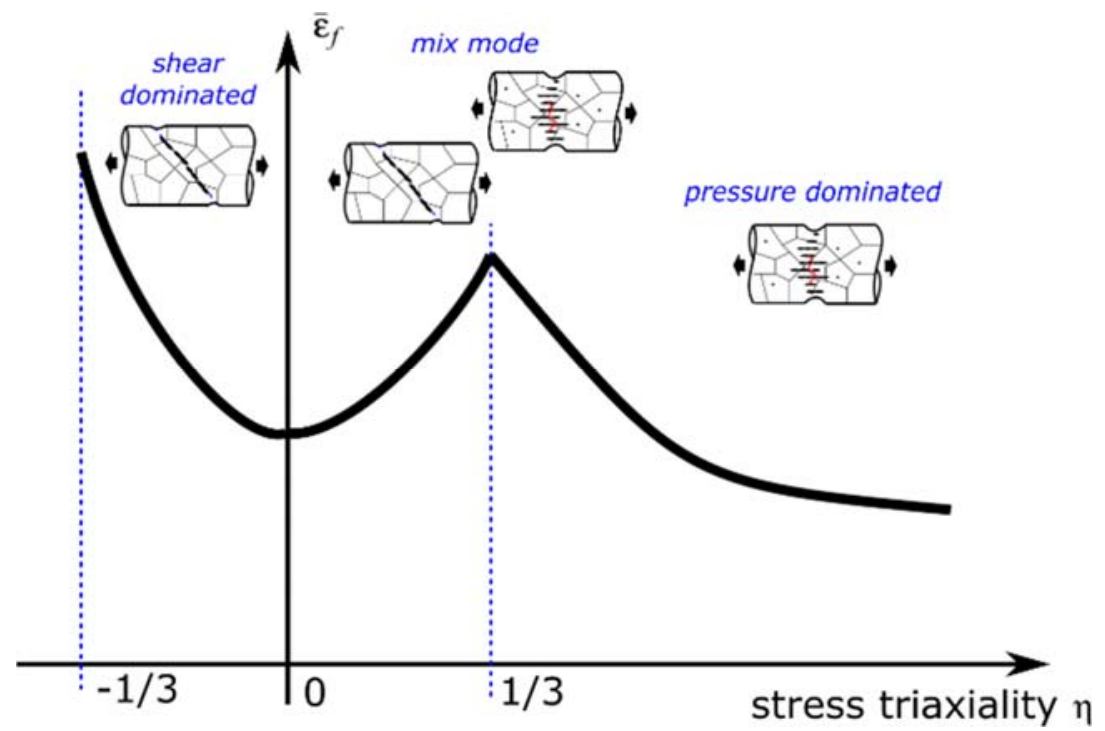

Figure 4: Typical dependency of the equivalent strain to fracture on the stress triaxiality.

An important aspect in the numerical modeling of the damaging process consisted, and still consists, in formulating a constitutive law for the description of the evolution of the $D$ variable, from the non-damaged state until the final failure. In particular, the challenge is represented by formulating the simplest law that includes the main factors governing the void nucleation, growth and coalescence. The extensive experimental campaign conducted in the second half of the last century [52-58] pointed out the dependency of the damage process on a dimensionless stress parameters: the stress triaxiality $\eta$ (e.g.,[59-63]). In fact, for metallic materials was found that the ductile fracture mechanism and final deformation to fracture (i.e., equivalent strain to fracture $\bar{\varepsilon}_{f}$ ) are strongly related to the magnitude of the stress triaxiality (Fig. 4). While the effect of the stress triaxiality has been initially incorporated in most of the constitutive models for the description of metal failure, the role of the Lode angle [59] $\theta$ became evident later, when experiments under different loading conditions showed that the equivalent strain to fracture changes for different values of the Lode angle under the same stress triaxiality. The effect of the Lode angle is often taken into account by introducing the Lode angle parameter $\bar{\theta}$ (e.g., [59-66]), a dimensionless scalar variable that assumes values between -1 and +1 ( -1 in case of compression, 0 in case of shear or plane stress condition and +1 for tension), see Fig. 5. Most of the recent constitutive models account for damage evolution laws that consider the effects of both stress triaxiality and Lode angle parameters.

\section{Ductile damage models}

The ductile damage evolution and fracture prediction represent the central points for the scientific and engineering community in the framework of material failure. Several works have been carried out developing various theories for the description of the damage. In the literature they can be divided into three main categories:

- Group I: Empirical failure criteria.

- Group II: Phenomenological models. 
- Group III: Micromechanics-based models.

It should be mentioned that the classification of the theories is not unique. In this work, the classification proposed by De Souza Neto et al. [67], Besson [68] and others [6,69] is followed. Sometimes, group II is referred as continuum damage mechanics (CDM) models (e.g. [70,71]). In this work it is considered that both group II and group III belong to the CDM framework since they both offer a continuous description of the damage.

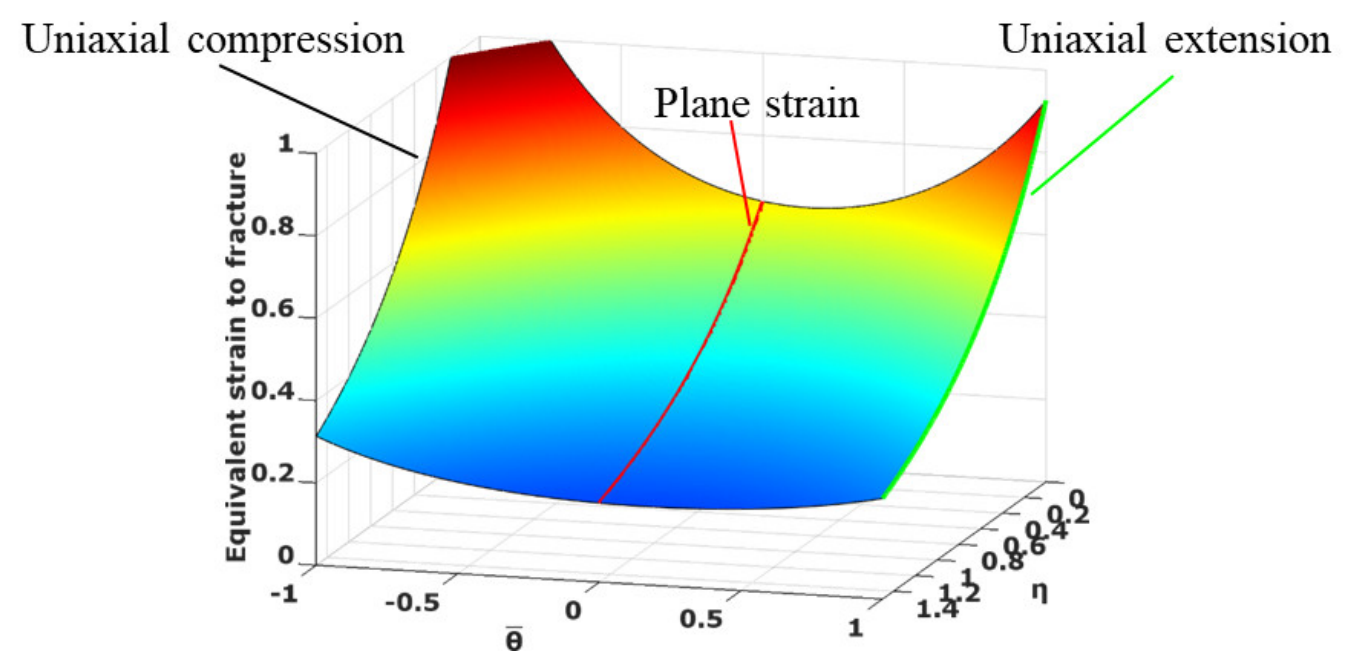

Figure 5: Typical dependency of the equivalent strain to fracture on the Lode angle parameter.

Group I. To this first category belong the models that consider the damaging process as independent form the plastic behavior of the material. Often in the literature this approach is referred as 'uncoupled' meaning that the damage internal variable has no influence on the other plastic internal variables nor the elastic properties of the material and vice versa. Therefore, the variable $D$ is merely indicator of the state of the material without an actual contribution on the degradation of the mechanical properties. Due to their simplicity, the empirical failure criteria spread widely, especially for industrial applications [72].

The Cockcroft-Latham criterion [73] and its subsequent modification into the Cockcroft-Latham-Oh [74] represent a widely used criteria for the prediction of the rapture. In the last decade, several papers and technical reports adopted this approach due to its simplicity and the extremely low number of parameters required. On the other side, due to their simple form, they do not consider the effect of the Lode angle and returns qualitative results in case of significant variation of the stress state. Wilkins et al. [54] tried to consider the effect of the stress triaxiality together with the Lode angle, where the Lode angle was considered by a scalar factor $A$ that describes the stress asymmetry of the principal stress deviators. A good description of the rapture under different stress states can be obtained if the material does not show a pronounced Lode angle sensitivity. Johnson and Cook [53] developed a material constitutive model that is still widely used. In particular, even if the Lode angle effect is still neglected, this approach includes the effect of the strain rate and temperature beside the stress triaxiality. Its calibration requires the definition of a total of 8 material parameters, which can be reduced to 3 in case of quasi-static and isothermal conditions. The J-C criteria is particularly suitable to predict failure at impact or high rate loading conditions [75]. Recently, Bai and Wierzbicki [60] proposed a modified Mohr-Coulomb criterion (MMC) for the prediction of ductile fracture. The MMC can take into consideration the effect of the stress triaxiality and Lode angle and it requires a total of 8 material parameters in its general form, or 4 material parameters in case a von Mises yield function is assumed. This last criterion seems to predict quite accurately the ductile failure and it has found a large application in the recent literature.

A comparative study on failure criteria is offered in [76]. An interesting work by Bao and Wierzbicki [77] pointed out that all the aforementioned criteria are not able to describe the material failure under a wide range of stress triaxiality. Modifications of the criteria are needed in case of low or negative values of the stress triaxiality. Moreover, it should be also pointed out that the construction of the failure envelope (i.e., locus of the final strain to fracture as a function of the stress triaxiality and/or Lode angle parameter) is valid only for proportional loading paths. Exceptions are represented by the use of empirical criteria coupled with plastic internal variables [64,78-80]. A recent interesting work from Ganjiani and Homayounfard [81] presented a ductile failure criterion based on an analytical definition of the plastic strain onset of the fracture capable to account for proportional and non-proportional loading conditions. The coupled elastoplastic and damage model in [81] can consider plastic anisotropy by means of the Hill48 yield criterion [82] and resulted in a good prediction 
of the failure mechanism of several materials (i.e., Al6012-T6 and Al2024-T351 aluminums, A533B and 1045 steels). The work of Wang et al. [83] proposed a novel criterion for metal failure under cyclic loading coupled with an innovative elastoplastic model. The advantages of this theory consist of a simple numerical procedure and the possibility to predict cracks formation at low and high cycle fatigue. A recent uncoupled ductile fracture criterion has been proposed by Quanch et al. [84] focusing the attention on the micro-mechanism of void nucleation, growth and coalescence. Moreover, their work investigated the material failure considering the anisotropic behavior of 6016-AC200 aluminum under a wide range of stress states.

Group II. The phenomenological models describe the damaging process from a macroscopic point of view. This class of theories developed from the initial work of Kachanov [85] and Rabotnov [86], who tried to give a first physical characterization of the damage as the reduction of the resisting area in the material. The damage concept was later consolidated in a consistent thermodynamic framework by Lemaitre $[87,88]$.

Lemaitre's model is based on two assumptions:

- effective stress tensor 'as the stress to be apply to a non-damaged element of material so it deforms as damage element under the actual current stress' [68].

- strain equivalence as 'the strain behavior of a damage material is represented by the constitutive equation of the non-damaged material, using the effective stress'. Alternatively, Saanouni et al. [89] proposed the hypothesis of energy equivalence to define the constitutive variables governing the damaging process. In case of material anisotropy the energy equivalence should be adopted $[6,90])$.

From the Lemaitre's initial formulation several theories were developed. All of them can be considered as phenomenological since the micro-cracks or voids inside the material are not considered individually but they are 'smeared' in the media. In this sense the constitutive equations describe the overall macroscopic response of the damaged material. As mentioned before, group II models are derived from a consistent thermodynamic framework which allows different type of couplings between the damage and the elasto-plastic internal variables depending on the free energy definition [6]. It also allows the definition of several types of non-negative dissipation potential and yield functions.

The Lemaitre's formulation $[87,88]$ considered uniquely the effect of the stress triaxiality. Recent developments of the theory formulated the damage evolution as a function of the Lode angle parameter [66,91-95]. Phenomenological models were also developed in a finite strain framework accounting for material anisotropy [47,96-98] improving the material description in several industrial processes with large plastic straining. As for the empirical failure criteria, the calibration of the material parameter should be carried out carefully. Nonetheless, depending on the material, it can be still difficult to characterize the failure behavior under a wide range of the stress triaxiality and Lode angle parameter. Moreover, group II models usually need the calibration of several material parameters.

Group III. The pioneering work in this category was undertaken by McClintock [99] and Rice and Tracey [62] who formulated the first two damage criteria based on geometrical observations on a defect inside a material matrix. These two initial works laid the foundations for the damage criterion which considered the material failure whenever the normalized void radius reached a critical value. Gurson [100] was the first to consider the interaction between the voids and the their growth and the material response in terms of stress and strain. He re-formulated the yield criterion adding the contribution of the volume of the voids and, in detail, he associated the damage evolution with the porosity $f$, or void volume fraction. The influence of the damage on the plastic flow was therefore included in the porosity that progressively shrinks the plastic potential. The failure is assumed for $f=1$, similarly to the concept expressed in Eq. (1). Further development of the model led to the well-known Gurson-Tvergaard-Needleman (GTN) model. The improvement consisted in a better description of the void nucleation, growth, and coalescence mechanism with a more realistic description of the material failure. It should be pointed out that micromechanics-based models are not derived from a consistent thermodynamical framework (with the exception of the hybrid model proposed by Rousselier [63], even though it should be considered in a group of its own), where the damage evolution is not associated with a dissipative mechanism.

The GTN approach and its subsequent developments proved to have a high predictive capability at high stress triaxiality. Unfortunately, the model does not perform well at low stress triaxiality and in case of pure shear, where no void growth is generated. To overcome these drawbacks, recent modifications of the original GTN model were carried out. [101-106], however, with an increase of material parameters. Moreover, the inclusion of the effect of the third invariant with the introduction of the Lode angle parameter was carried out on a phenomenological approach and micro-mechanical justification was not given. The motivation for the poor performance of the GTN model at low stress triaxiality lies on the assumption that spherical voids remain spherical, which does not seem to be accurate. Therefore, Jiang et al. [107] proposed a model based on a duplex mechanism, one for the void growth and one for void shear. Their results seem to be in good agreement with experimental data for a wide range of stress triaxiality and Lode angles. 
Even in case of micromechanics-based constitutive models the number of material parameters to be calibrated can be considerable, especially in the recent development of the GTN model. Moreover, some of the material parameters should be characterized by micromechanical analyses and cannot be identified by conventional mechanical tests.

\section{MODELS COMPARISON AND COMPUTATIONAL ASPECTS}

$\mathrm{E}$ ven though the choice of the best model or criteria for the description of the ductile behavior depends on the single model itself, in the present section a general comparison among the group I, group II, and group III models is given. The main aspects will be presented in the following bullet points.

- Elastic behavior. Among the three groups, the damage plays an important role on the elastic stiffness only in the models derived by the Lemaitre's concept. The damage internal variable can be coupled with the elastic free energy for the definition of the elasto-damage behavior. However, it is also possible to couple the damage variable uniquely with the plastic variables, or to regulate the effect on the material stiffness as suggested by Xue [108]. Moreover, to diversify the model elastic response in tension or compression it is possible to simulate the crack closure effect with the addition of one scalar material parameter [109]. Uncouples models of group I, clearly do not consider the effect of the damage on the elastic behavior. In general, the models derived by the GTN concept do not consider the mechanical degradation of the elastic properties. Experimental evidence showed that the effect of the damage on the elastic properties is limited, it can become more visible in case of cyclic loading upon failure.

- Plastic volume change. Models of group I or II, in general, do not consider the plastic volume changes. The firsts since there is no coupling with the damage. The seconds because only the stress deviator or the effective stress deviator is used in the formulation of the yield potential. Consequently, micromechanics-based models are the only one to fulfill the mass conservation, since the damage evolution law is directly based on the evolution of the void volume fraction. It should be pointed out that few attempts have been made to include the effect of the porosity in phenomenological models such as the work of Hammi and Horstemeyer [110] even though the volume change is not actually accounted for. Santaoja [111] recently published a paper presenting a phenomenological model where the damage variable was redefined to take into account the void volume fraction. However, this model considers an elastic matrix response with spherical microvoids only.

- Strain induced anisotropy. Strain induced anisotropy can be easily taken into account in uncoupled or Lemaitre's type models, since the implementation of kinematic hardening laws is straightforward. The initial GTN model does not consider the effect of kinematic hardening and it was based on isotropic hardening only. Recent versions of the GTN model overcame this drawback and can consider the contribution of the kinematic hardening (e.g., [112]).

- Plastic anisotropy and anisotropic ductile damage. While it is possible to consider plastic anisotropic by means of anisotropic yield criteria [82,113-115], an anisotropic damage variable has been described by several approaches in group II. A first strategy consists in describing the damage by means of set of vectors associated with predefined directions [116,117]. Alternatively, the damage can be described by second-order tensors [48,118,119] even though a second-order damage tensor itself can not properly describe the damage induced anisotropy in the fourth order elastic tensor. Lastly, the damage can be described by a fourth-order tensor which is derived consistently from the effective stress concept, and it has been widely adopted in the literature [97,120-122]. However, recent works showed the possibility to use a scalar damage variable to model an anisotropic damaging process [51,123]. These approaches, even if not representative of the true nature of an anisotropic damage variable, can be still useful in several engineering applications. In GTN-type models the anisotropic evolution of the void (and therefore of the damage) can be considered by adopting ad hoc laws with shape factors $[124,125]$ that describes the volume and shape changes of the voids as well as their rotation during the loading process. The consideration of the void shape changes and reorientation complicates the formulation of group III models and their validation on three dimensional problems with complex loading conditions remains challenging.

- Rate and temperature dependencies. From experimental observations, metals seems to show an increase in ductility with the strain rate (found in steel, aluminum, copper, titanium etc.) [126]. The formulation of group I models with deformation rate dependency or temperature dependency can be easily done by adding ad-hoc terms to the failure criteria. In coupled models the effect of the rate-sensitivity and temperature should be taken into account both in the deformation and damaging processes. The development of rate-dependent and temperature dependent Lemaitre's type models is quite straightforward $[108,127,128]$ and it requires simple modification with the addition of few material 
parameters. On the other side, micromechanical investigation for the formulation of the rate-dependency and temperature dependency GTN-type models seems more complex.

- Mesh sensitivity. Due to the uncoupled nature of the constitutive equations, models in group I are less influenced by the mesh size but can however suffer from strain localizations problems. On the contrary, due to the material softening induced by the damage evolution, mesh sensitivity is an important issue for models of group II and III [129]. From a theoretical point of view, the boundary problem becomes ill-posed once the deformation and damage accumulates in few elements. To prevent this problem several methods were proposed (i.e., viscoplastic regularization, non-local theories, gradient-like definition of the internal variables). Most commonly, a spatial averaging term is adopted, where it is assumed that the value of the state variables (damage, plastic deformations) in a local point depends on the values of the state variables in the neighborhood of the point. This concept adopts a characteristic length to define a domain (area or volume) used to average the damage variable and avoid the localization and consequent softening in single elements $[130,131]$. Unfortunately, in commercial software it is difficult to implement such strategy even with the use of user-subroutines. Another solution is represented by models adopting the definition of gradient-like formulation of the internal variables [132-134]. Alternatively, a common and easy solution is to set a value of the critical damage $D_{c}$ small enough (0.2 0.3) to avoid localization. This strategy has also the benefit of avoiding an excessive loss of stiffness which leads to the loss of quadratic rate of convergence if an implicit numerical scheme is used for the integration of the constitutive equations [67].

- Proportional, non-proportional loading conditions. The use of empirical criteria for the description of the damage evolution should be limited to proportional loading only. However, the use of empirical criteria where the damage and plastic variables are coupled showed good agreement with experimental data on material failure under nonproportional loading paths $[79,81,135,136]$. Example of the applications of the Lemaitre-type and GTN-type models to non-proportional loading can be found in [137,138].

- Calibration of the mechanical parameters. A common practice for the calibration of the material constants of the models in all groups is to conduct inverse and parametric studies to fit the experimental curves. In detail, knowing the force-displacement curve for a sample together with the final elongation to fracture, the calibration is conducted to identify the set of parameters, within their ranges of existence, that minimizes the differences between the experimental and numerical curves. The uncoupled nature of the models in group I allows to distinguish between the calibration of the elastoplastic constants and the parameters for the damage evolution law, leaving to the firsts the fitting of the experimental force-displacement trend and to the seconds the description of the final elongation to fracture. On the other hand, the coupled nature of models in group II and III requires the elastoplastic and damage parameters to be identified simultaneously. From a theoretical point of view, the constants for models in group III should be based on micro-mechanicals investigations. However, often the parameters for the GTN-type models are obtained from macroscopic mechanical tests due to costs of ad hoc experimental investigations and due to the phenomenological formulation of some laws, for instance the Lode angle dependency.

Recently, several authors combined the use of finite element modeling and artificial intelligence (AI) for the numerical characterization of ductile failure. This methodology seems promising and gave accurate predictions, however, it still relies on the size and quality of the experimental database to train the AI algorithm. Baltic et al. [139] combined FE and artificial neural network (ANN) to calibrate a GTN-type model on a single sample. The main advantage is the possibility of extracting the model parameters from a single sample as opposed to the many geometries usually necessary to define the locus of the strain to failure. Moreover, the ANN algorithm showed a good performance in calibration even with limited data available for the training and learning. Quan et al. [140] adopted ANN to identify the damage parameters of the shear modified GTN model [141] in a small punch test. The numerical simulations reproduced accurately the experimental tests.

The following Tab. 1 offers a list of the advantages and shortcomings of the different approaches for modeling the metallic material failure.

\section{CONCLUSIONS}

7 he present work aims to offer useful information for the characterization of the ductile damaging phenomenon. Initial considerations were described to distinguish the different damaging mechanisms that might take place in metallic materials. Among them, ductile fracture has relevant role in many industrial applications and therefore it 
has been widely investigated leading to the generation of predictive models with the intent of improving the design and service life of components/structures.

Experimental characterization of the damage is another fundamental aspect to reach a reliable numerical modeling of the phenomena, and at the same time to offer a tool for the maintenance of existing structures. Several techniques have been described and reported.

Lastly, three different classes of numerical approaches have been introduced, giving a brief summary of their main features. In detail, the previous section discussed the strong and weak points of each theory. The reader should be reminded that the choice of the computational model should depends on the specific case to analyze and the possibility to characterize the material parameters. Clearly the choice of a particular constitutive model should be balanced between its simplicity and the predictive capability in relation to the problem to solve. A judgment on the best model based on the constitutive equations themselves cannot be objective. The authors tried to report the most recent relevant literature in order to offer a view on the state of the art in metal ductility and failure.

\section{Advantages}

Disadvantages

- application on proportional loadings only (except for models with coupled damage and

- simple application in FE;

- negligible mesh dependency;

- stress triaxiality and Lode angle;

- plastic anisotropy of the material matrix.

- thermodynamically consistent;

- coupling damage and elasticity;

- easy implementation of kinematic hardening;

Group II

- stress triaxiality and Lode angle dependency;

- proportional and non-proportional loading path;

- anisotropy of the material matrix.

- fulfilment of mass conservation

- stress triaxiality and Lode angle dependency;

Group III

- proportional and non-proportional loading plastic variables);

- lack of physical meaning;

- different functions to predict failure at different triaxialities;

- no influence of the damage on the plastic variables and vice versa (except for models with coupled damage and plastic variables).

- mesh dependency;

- does not fulfil mass conservation;

- no physical parameters involved;

- requires to include Lode angle parameter for shear failure. paths.

- mesh dependency;

- coupling damage and elasticity requires an ad hoc formulation;

- requires ad hoc formulation of kinematic hardening;

- Lode angle dependency does not have micromechanical justification;

- requires a lot of material parameters;

- material parameters calibration requires micromechanical tests;

- requires 'phenomenological' modification to model low stress triaxiality damaging.

Table 1: Summary of the features of the group I, II and III models.

\section{REFERENCES}

[1] Takazawa, H., Iwamatsu, F., Miyazaki, K. (2013). OS1428 Evaluation of Ductile Fracture Using GTN Model in Commercial FEA Code, Proc. Mater. Mech. Conf., 2013, pp._os1428-1_-_os1428-3_

DOI: $10.1299 /$ jsmemm.2013._OS1428-1_. 
[2] Ikushima, K., Yano, T., Natsume, R., Shibahara, M., Ohata, M. (2017). Study on fracture mode of spot weld joint using continuum damage mechanics model, Q. J. Japan Weld. Soc., 35(2), pp. 28s-32s, DOI: 10.2207/qjjws.35.28s.

[3] Watanabe, I. (2015). Multiscale Modeling of Ductile Fracture in Continuum Mechanics, Tetsu-to-Hagane, 101(9), pp. 465-470, DOI: 10.2355/tetsutohagane.TETSU-2015-022.

[4] Sugiyama, H., Matsui, K., Endo, T., Yamada, T. (2014). Propagation of discontinuities with damage model, Proc. Comput. Mech. Conf., 2014.27, pp. 473-474, DOI: 10.1299/jsmecmd.2014.27.473.

[5] Pantazopoulos, G. (2019). A Short Review on Fracture Mechanisms of Mechanical Components Operated under Industrial Process Conditions: Fractographic Analysis and Selected Prevention Strategies, Metals (Basel)., 9(2), pp. 148, DOI: $10.3390 / \operatorname{met} 9020148$.

[6] Besson, J., Forest, S., Cailletaud, G., Blétry, M., Chaboche, J.L. (2010). Non-linear mechanics of materials, Solid Mech. Its Appl., DOI: 10.1007/978-90-481-3356-7_1.

[7] Noell, P.J., Carroll, J.D., Boyce, B.L. (2018). The mechanisms of ductile rupture, Acta Mater., 161, pp. 83-98, DOI: $10.1016 /$ j.actamat.2018.09.006.

[8] Wada, Y., Ueda, K. (2019). Evaluation of equivalent plastic strain and stress triaxiality and $\Delta \mathrm{J}$ for proposing a crack growth formula under extremely low cycle fatigue, Proc. Comput. Mech. Conf., 2019.32, pp. 092, DOI: $10.1299 /$ jsmecmd.2019.32.092.

[9] Sawamoto, Y., Kubota, J., Ohsaki, M. (2020). Evaluation on plastic deformation capacity of steel beam ends with local buckling andfracture under cyclicloading using FE analysis, J. Struct. Constr. Eng. (Transactions AIJ), 85(767), pp. 105115, DOI: $10.3130 /$ aijs.85.105.

[10] Kimura, K., Tomioka, N., Okabe, A. (2019). High Cycle Fatigue Damage of Steel Sheet used in Vehicle Body, Proc. Mater. Mech. Conf., 2019, pp. gs14, DOI: 10.1299/jsmemm.2019.GS14.

[11] Pantazopoulos, G. (2002). Leaded Brass Rods C 38500 for Automating Machining Operations: A Technical Report, J. Mater. Eng. Perform., 11(4), pp. 402-407, DOI: $10.1361 / 105994902770343926$.

[12] Lynch, S.P., Moutsos, S. (2006). A brief history of fractography, J. Fail. Anal. Prev., DOI: 10.1361/154770206X156231.

[13] Lu, M., Wang, F., Zeng, X., Chen, W., Zhang, J. (2020). Cohesive zone modeling for crack propagation in polycrystalline NiTi alloys using molecular dynamics, Theor. Appl. Fract. Mech., 105, pp. 102402, DOI: 10.1016/j.tafmec.2019.102402.

[14] Margolin, B., Karzov, G., Shvetsova, V., Kostylev, V. (2002). Modelling for transcrystalline and intercrystalline fracture by void nucleation and growth, Fatigue Fract. Eng. Mater. Struct., 21(2), pp. 123-137, DOI: $10.1046 / j .1460-2695.1998 .00474 . x$.

[15] Sun, Z., Benabou, L., Xue, H. (2016). Numerical modeling and simulation of intergranular fracture due to dynamic embrittlement for a CuNiSi alloy, Mech. Res. Commun., 75, pp. 81-88, DOI: 10.1016/j.mechrescom.2016.06.003.

[16] Ikeya, H., Umezawa, O., Fukutomi, H. (2019). Crystal lattice rotation and fatigue crack generation in aluminum wire under cyclic bending deformation, J. Japan Inst. Light Met., 69(6), pp. 302-208, DOI: 10.2464/jilm.69.302.

[17] Alderliesten, R. (2017).Fatigue crack propagation. Solid Mechanics and its Applications.

[18] He, L., Akebono, H., Sugeta, A., Hayashi, Y. (2020). Cumulative fatigue damage of stress below the fatigue limit in weldment steel under block loading, Fatigue Fract. Eng. Mater. Struct., 43(7), pp. 1419-1432, DOI: 10.1111/ffe.13204.

[19] Sakai, T. (2009). Review and Prospects for Current Studies on Very High Cycle Fatigue of Metallic Materials for Machine Structural Use, J. Solid Mech. Mater. Eng., 3(3), pp. 425-39, DOI: 10.1299/jmmp.3.425.

[20] Tang, L., Ince, A., Zheng, J. (2020). Numerical modeling of residual stresses and fatigue damage assessment of ultrasonic impact treated 304L stainless steel welded joints, Eng. Fail. Anal., 108, pp. 104277, DOI: $10.1016 /$ j.engfailanal.2019.104277.

[21] Borges, M.F., Neto, D.M., Antunes, F.V. (2020). Numerical simulation of fatigue crack growth based on accumulated plastic strain, Theor. Appl. Fract. Mech., 108, pp. 102676, DOI: 10.1016/j.tafmec.2020.102676.

[22] Tanaka, N., Saitou, Y., Matsumura, T. (2019). Very high cycle fatigue properties and damage mechanism of cast aluminum alloy, Proc. Mater. Mech. Conf., pp. os0905, DOI: 10.1299/jsmemm.2019.OS0905.

[23] Nowak, K. (2020). Application of a nonlocal grid model for analysis of the creep damage of metals, Int. J. Damage Mech., 29(5), pp. 780-797, DOI: 10.1177/1056789519883668.

[24] Meng, Q., Wang, Z. (2019). Creep damage models and their applications for crack growth analysis in pipes: A review, Eng. Fract. Mech., 205, pp. 547-576, DOI: 10.1016/j.engfracmech.2015.09.055.

[25] Liu, Y., Murakami, S. (1998). Damage Localization of Conventional Creep Damage Models and Proposition of a New Model for Creep Damage Analysis., JSME Int. J. Ser. A, 41(1), pp. 57-65, DOI: 10.1299/jsmea.41.57.

[26] Zheng, X., Xu, Q., Lu, Z., Wang, X., Feng, X. (2020). The development of creep damage constitutive equations for high Cr steel, Mater. High Temp., 37(2), pp. 129-138, DOI: 10.1080/09603409.2020.1716145.

[27] Yamazaki, N., Nomura, K., Kubushiro, K. (2020). Creep-Fatigue Damage for Boiler Header Stub Mock-Up Specimen 
of 47Ni-23Cr-23Fe-7W Alloy, Mater. Trans., 61(6), pp. 1109-1114, DOI: 10.2320/matertrans.Z-M2020813.

[28] Koiwa, K., Tabuchi, M., Demura, M., Yamazaki, M., Watanabe, M. (2019). Prediction of Creep Rupture Time Using Constitutive Laws and Damage Rules in 9Cr-1Mo-V-Nb Steel Welds, Mater. Trans., 60(2), pp. 213-221, DOI: $10.2320 /$ matertrans.ME201703.

[29] Oliver, W.C., Pharr, G.M. (1992). An improved technique for determining hardness and elastic modulus using load and displacement sensing indentation experiments, J. Mater. Res., 7(06), pp. 1564-1583, DOI: 10.1557/JMR.1992.1564.

[30] Zhang, S., Xia, Q., Li, W., Zhou, X. (2014). Ductile damage measurement and necking analysis of metal sheets based on digital image correlation and direct current potential drop methods, Int. J. Damage Mech., 23(8), pp. 1133-1149, DOI: $10.1177 / 1056789514527978$.

[31] Mastrone, M.N., Fraccaroli, L., Concli, F. (2021). Ductile damage model of an alluminum alloy: experimental and numerical validation on a punch test, Int. J. Comput. Methods Exp. Meas., 9(3), pp. 249-260, DOI: 10.2495/CMEM-V9-N3-249-260.

[32] Lemaitre, J., Dufailly, J. (1987). Damage measurements, Eng. Fract. Mech., 28(5-6), pp. 643-661, DOI: 10.1016/0013-7944(87)90059-2.

[33] Kumar, J., Padma, S., Srivathsa, B., Rao, N.V., Kumar, V. (2009). Evolution of Damage in Near $\alpha$ IMI-834 Titanium Alloy Under Monotonic Loading Condition: A Continuum Damage Mechanics Approach, J. Eng. Mater. Technol., 131(3), pp. 031012, DOI: 10.1115/1.3086384.

[34] Goldstein, J.I., Newbury, D.E., Michael, J.R., Ritchie, N.W.M., Scott, J.H.J., Joy, D.C. (2017). Scanning electron microscopy and $\mathrm{x}$-ray microanalysis.

[35] Hutiu, G., Duma, V.-F., Demian, D., Bradu, A., Podoleanu, A. (2018). Assessment of Ductile, Brittle, and Fatigue Fractures of Metals Using Optical Coherence Tomography, Metals (Basel)., 8(2), pp. 117, DOI: 10.3390/met8020117.

[36] Shan, Z.W., Mishra, R.K., Syed Asif, S.A., Warren, O.L., Minor, A.M. (2008). Mechanical annealing and source-limited deformation in submicrometre-diameter Ni crystals, Nat. Mater., 7(2), pp. 115-119, DOI: 10.1038/nmat2085.

[37] Ly, T.H., Zhao, J., Cichocka, M.O., Li, L.-J., Lee, Y.H. (2017). Dynamical observations on the crack tip zone and stress corrosion of two-dimensional MoS2, Nat. Commun., 8(1), pp. 14116, DOI: 10.1038/ncomms14116.

[38] Wang, L., Teng, J., Sha, X., Zou, J., Zhang, Z., Han, X. (2017). Plastic Deformation through Dislocation Saturation in Ultrasmall Pt Nanocrystals and Its in Situ Atomistic Mechanisms, Nano Lett., 17(8), pp. 4733-4739, DOI: $10.1021 /$ acs.nanolett.7b01416.

[39] Zhang, J., Li, Y., Li, X., Zhai, Y., Zhang, Q., Ma, D., Mao, S., Deng, Q., Li, Z., Li, X., Wang, X., Liu, Y., Zhang, Z., Han, X. (2021). Timely and atomic-resolved high-temperature mechanical investigation of ductile fracture and atomistic mechanisms of tungsten, Nat. Commun., 12(1), pp. 2218, DOI: 10.1038/s41467-021-22447-y.

[40] Cao, T.-S., Maire, E., Verdu, C., Bobadilla, C., Lasne, P., Montmitonnet, P., Bouchard, P.-O. (2014). Characterization of ductile damage for a high carbon steel using 3D X-ray micro-tomography and mechanical tests - Application to the identification of a shear modified GTN model, Comput. Mater. Sci., 84, pp. 175-187, DOI: $10.1016 /$ j.commatsci.2013.12.006.

[41] Maire, E., Bouaziz, O., Di Michiel, M., Verdu, C. (2008). Initiation and growth of damage in a dual-phase steel observed by X-ray microtomography, Acta Mater., 56(18), pp. 4954-4964, DOI: 10.1016/j.actamat.2008.06.015.

[42] Weck, A., Wilkinson, D.S., Maire, E., Toda, H. (2008). Visualization by X-ray tomography of void growth and coalescence leading to fracture in model materials, Acta Mater., 56(12), pp. 2919-2928, DOI: $10.1016 /$ j.actamat.2008.02.027.

[43] Cao, T.-S., Maire, E., Verdu, C., Bobadilla, C., Lasne, P., Montmitonnet, P., Bouchard, P.-O. (2014). Characterization of ductile damage for a high carbon steel using 3D X-ray micro-tomography and mechanical tests - Application to the identification of a shear modified GTN model, Comput. Mater. Sci., 84, pp. 175-187,

DOI: 10.1016/j.commatsci.2013.12.006.

[44] Boccaccini, D.N., Boccaccini, A.R. (1997). Dependence of Ultrasonic Velocity on Porosity and Pore Shape in Sintered Materials, J. Nondestruct. Eval., 16(4), pp. 187-192, DOI: 10.1023/A:1021891813782.

[45] Chiantoni, G., Comi, C., Mariani, S., Bonora, N. (2014). Experimental assessment of ductile damage in P91 steel at high temperature, Int. J. Damage Mech., 23(4), pp. 567-587, DOI: 10.1177/1056789513503972.

[46] Bonora, N., Ruggiero, A., Gentile, D., De Meo, S. (2011). Practical Applicability and Limitations of the Elastic Modulus Degradation Technique for Damage Measurements in Ductile Metals, Strain, 47(3), pp. 241-254, DOI: $10.1111 /$ j.1475-1305.2009.00678.x.

[47] Rajhi, W., Saanouni, K., Sidhom, H. (2014). Anisotropic ductile damage fully coupled with anisotropic plastic flow: Modeling, experimental validation, and application to metal forming simulation, Int. J. Damage Mech., 23(8), pp. 12111256, DOI: $10.1177 / 1056789514524076$. 
[48] Reese, S., Brepols, T., Fassin, M., Poggenpohl, L., Wulfinghoff, S. (2021). Using structural tensors for inelastic material modeling in the finite strain regime - A novel approach to anisotropic damage, J. Mech. Phys. Solids, 146, pp. 104174, DOI: $10.1016 /$ j.jmps.2020.104174.

[49] Javani, H.R., Peerlings, R.H.J., Geers, M.G.D. (2016). Three-dimensional finite element modeling of ductile crack initiation and propagation, Adv. Model. Simul. Eng. Sci., 3(1), pp. 19, DOI: 10.1186/s40323-016-0071-y.

[50] Yang, F., Veljkovic, M., Liu, Y. (2020). Ductile damage model calibration for high-strength structural steels, Constr. Build. Mater., 263, pp. 120632, DOI: 10.1016/j.conbuildmat.2020.120632.

[51]Zhang, H., Zhang, H., Li, F., Cao, J. (2019). A Novel Damage Model to Predict Ductile Fracture Behavior for Anisotropic Sheet Metal, Metals (Basel)., 9(5), pp. 595, DOI: 10.3390/met9050595.

[52] Hancock, J.W., Mackenzie, A.C. (1976). On the mechanisms of ductile failure in high-strength steels subjected to multiaxial stress-states, J. Mech. Phys. Solids, 24(2-3), pp. 147-160, DOI: 10.1016/0022-5096(76)90024-7.

[53] Johnson, G.R., Cook, W.H. (1985). Fracture characteristics of three metals subjected to various strains, strain rates, temperatures and pressures, Eng. Fract. Mech., 21(1), pp. 31-48, DOI: 10.1016/0013-7944(85)90052-9.

[54] Wilkins, M.L., Streit, R.D., Reaugh, J.E. (1980). Cumulative-strain-damage model of ductile fracture: simulation and prediction of engineering fracture tests, Livermore, CA.

[55] Clausing, D.P. (1970). Effect of plastic strain state on ductility and toughness, Int. J. Fract. Mech., 6(1), DOI: $10.1007 / \mathrm{BF} 00183662$.

[56] Bridgman, P.W. (1952). Studies in large plastic flow and fracture: with special emphasis on the effects of hydrostatic pressure, Cambridge, MA, Harvard University Press.

[57] McClintock, F.A. (1971).Plasticity aspects of fractures, chapter 2. Engineering Fundamentals and Environmental Effects, pp. 47-225.

[58] Toda, H., Tsuruta, H., Horikawa, K., Uesugi, K., Takeuchi, A., Suzuki, Y., Kobayashi, M. (2014). Effects of Stress Triaxiality on Damage Evolution from Pre-Existing Hydrogen Pores in Aluminum Alloy, Mater. Trans., 55(2), pp. 383386, DOI: 10.2320/matertrans.L-M2013841.

[59] Lode, W. (1926). Versuche uber den Einfluss der mittleren Hauptspannung auf das Fliess en der Metalle Eisen, Kupfer und Nickel, Zeitschrift Fur Phys., 36(11-12), pp. 913-939, DOI: 10.1007/BF01400222.

[60] Bai, Y., Wierzbicki, T. (2010). Application of extended Mohr-Coulomb criterion to ductile fracture, Int. J. Fract., 161(1), pp. 1-20, DOI: 10.1007/s10704-009-9422-8.

[61] Bonora, N. (1997). A nonlinear CDM model for ductile failure, Eng. Fract. Mech., 58(1-2), pp. 11-28, DOI: $10.1016 /$ S0013-7944(97)00074-X.

[62] Rice, J.R., Tracey, D.M. (1969). On the ductile enlargement of voids in triaxial stress fields, J. Mech. Phys. Solids, 17(3), pp. 201-217, DOI: 10.1016/0022-5096(69)90033-7.

[63] Rousselier, G. (1987). Ductile fracture models and their potential in local approach of fracture, Nucl. Eng. Des., 105(1), pp. 97-111, DOI: 10.1016/0029-5493(87)90234-2.

[64] Tsutsumi, S., Kitamura, T., Fincato, R. (2020). Ductile behaviour of carbon steel for welded structures: Experiments and numerical simulations, J. Constr. Steel Res., 172, DOI: 10.1016/j.jcsr.2020.106185.

[65] Cheng, L., Monchiet, V., Morin, L., de Saxcé, G., Kondo, D. (2015). An analytical Lode angle dependent damage model for ductile porous materials, Eng. Fract. Mech., 149, pp. 119-133, DOI: 10.1016/j.engfracmech.2015.09.038.

[66] Cao, T.S., Gachet, J.M., Montmitonnet, P., Bouchard, P.O. (2014). A Lode-dependent enhanced Lemaitre model for ductile fracture prediction at low stress triaxiality, Eng. Fract. Mech., 124-125, pp. 80-96, DOI: 10.1016/j.engfracmech.2014.03.021.

[67] de Souza Neto, E.A., Peric, D., Owen, D.R.J. (2008). Computational Methods for Plasticity, 55.

[68] Besson, J. (2010). Continuum Models of Ductile Fracture: A Review, Int. J. Damage Mech., 19(1), pp. 3-52, DOI: $10.1177 / 1056789509103482$.

[69] Malcher, L., Andrade Pires, F.M., César de Sá, J.M.A. (2012). An assessment of isotropic constitutive models for ductile fracture under high and low stress triaxiality, Int. J. Plast., 30-31, pp. 81-115, DOI: 10.1016/j.ijplas.2011.10.005.

[70] Cao, T.S. (2017). Models for ductile damage and fracture prediction in cold bulk metal forming processes: a review, Int. J. Mater. Form., 10(2), pp. 139-171, DOI: 10.1007/s12289-015-1262-7.

[71] Broggiato, G.B., Campana, F., Cortese, L. (2007). Identification of Material Damage Model Parameters: an Inverse Approach Using Digital Image Processing, Meccanica, 42(1), pp. 9-17, DOI: 10.1007/s11012-006-9019-5.

[72] Yamada, T., Ohata, M. (2020). Prediction of ductile crack growth resistance using mechanical properties of material, Q. J. Japan Weld. Soc., 38(2), pp. 85-94, DOI: 10.2207/qjjws.38.85.

[73] Cockcroft, M.G., Latham, D.J. (1968). Ductility and the workability of metals, J Inst Met. Inst. Met.

[74] Oh, S.I., Chen, C.C., Kobayashi, S. (1979). Ductile Fracture in Axisymmetric Extrusion and Drawing-Part 2: 
Workability in Extrusion and Drawing, J. Eng. Ind., 101(1), pp. 36-44, DOI: 10.1115/1.3439471.

[75] Rodriguez-Millan, M., Garcia-Gonzalez, D., Rusinek, A., Arias, A. (2018). Influence of Stress State on the Mechanical Impact and Deformation Behaviors of Aluminum Alloys, Metals (Basel)., 8(7), pp. 520, DOI: 10.3390/met8070520.

[76] Lou, Y., Huh, H. (2013). Evaluation of ductile fracture criteria in a general three-dimensional stress state considering the stress triaxiality and the lode parameter, Acta Mech. Solida Sin., 26(6), pp. 642-658, DOI: 10.1016/S0894-9166(14)60008-2.

[77] Bao, Y., Wierzbicki, T. (2004). On fracture locus in the equivalent strain and stress triaxiality space, Int. J. Mech. Sci., 46(1), pp. 81-98, DOI: 10.1016/j.ijmecsci.2004.02.006.

[78] Wu, B., Li, X., Di, Y., Brinnel, V., Lian, J., Münstermann, S. (2017). Extension of the modified Bai-Wierzbicki model for predicting ductile fracture under complex loading conditions, Fatigue Fract. Eng. Mater. Struct., 40(12), pp. 215268, DOI: $10.1111 /$ ffe.12645.

[79] Fincato, R., Tsutsumi, S. (2019). Numerical modeling of the evolution of ductile damage under proportional and nonproportional loading, Int. J. Solids Struct., 160, pp. 247-264, DOI: 10.1016/j.ijsolstr.2018.10.028.

[80] Erice, B., Gálvez, F. (2014). A coupled elastoplastic-damage constitutive model with Lode angle dependent failure criterion, Int. J. Solids Struct., 51(1), pp. 93-110, DOI: 10.1016/j.ijsolstr.2013.09.015.

[81] Ganjiani, M., Homayounfard, M. (2021). Development of a ductile failure model sensitive to stress triaxiality and Lode angle, Int. J. Solids Struct., 225, pp. 111066, DOI: 10.1016/j.ijsolstr.2021.111066.

[82] Hill, R. (1948). A theory of the yielding and plastic flow of anisotropic metals, Proc. R. Soc. London. Ser. A. Math. Phys. Sci., 193(1033), pp. 281-297, DOI: 10.1098/rspa.1948.0045.

[83] Wang, S., Zhan, L., Bruhns, O.T., Xiao, H. (2021). Metal failure effects predicted accurately with a unified and explicit criterion, ZAMM - J. Appl. Math. Mech. / Zeitschrift Für Angew. Math. Und Mech., DOI: 10.1002/zamm.202100140.

[84] Quach, H., Kim, J.J., Sung, J.H., Kim, Y.S. (2020). A novel uncoupled ductile fracture criterion for prediction of failure in sheet metal forming, IOP Conf. Ser. Mater. Sci. Eng., 967, pp. 012032, DOI: 10.1088/1757-899X/967/1/012032.

[85] Kachanov, L.M. (1958). Time of the rupture process under creep conditions, Izv Akad Nauk S S R Otd Tech Nauk, 8, pp. 26-31, DOI: citeulike-article-id:5466815.

[86] Rabotnov, Y.N. (1963). Paper 68: On the Equation of State of Creep, Proc. Inst. Mech. Eng. Conf. Proc., 178(1), pp. 2-117-2-122, DOI: 10.1243/PIME_CONF_1963_178_030_02.

[87] Lemaitre, J. (1985). Coupled elasto-plasticity and damage constitutive equations, Comput. Methods Appl. Mech. Eng., 51(1-3), pp. 31-49, DOI: 10.1016/0045-7825(85)90026-X.

[88] Lemaitre, J. (1985). A Continuous Damage Mechanics Model for Ductile Fracture, J. Eng. Mater. Technol., 107(1), pp. 83, DOI: $10.1115 / 1.3225775$.

[89] Saanouni, K., Forster, C., Hatira, F. Ben. (1994). On the Anelastic Flow with Damage, Int. J. Damage Mech., 3(2), pp. 140-169, DOI: $10.1177 / 105678959400300203$.

[90] Grammenoudis, P., Reckwerth, D., Tsakmakis, C. (2009). Continuum Damage Models based on Energy Equivalence: Part I - Isotropic Material Response, Int. J. Damage Mech., 18(1), pp. 31-63, DOI: 10.1177/1056789508090466.

[91] Zhang, K., Badreddine, H., Saanouni, K. (2020). Ductile fracture prediction using enhanced CDM model with Lode angle-dependency for titanium alloy Ti-6Al-4V at room temperature, J. Mater. Process. Technol., 277, pp. 116462, DOI: 10.1016/j.jmatprotec.2019.116462.

[92] Shinozuka, J., Goto, K. (2015). 10501 A FEM simulation of the serrated type of chip formation employing Lemaitre's damage model, Proc. Conf. Kanto Branch, 2015.21, pp. _10501-1_-_10501-2_

DOI: 10.1299/jsmekanto.2015.21._10501-1_.

[93] Fincato, R., Tsutsumi, S. (2017). Effect of the stress triaxiality and Lode angle on the ductile damage evolution, Q. J. Japan Weld. Soc., 35(2), pp. 185s-189s.

[94] Bonora, N., Testa, G., Ruggiero, A., Iannitti, G., Gentile, D. (2018). Modification of the Bonora Damage Model for shear failure, Frat. Ed Integrità Strutt., 12(44), pp. 140-150, DOI: 10.3221/IGF-ESIS.44.11.

[95] Bonora, N., Testa, G., Iannitti, G., Ruggiero, A., Gentile, D. (2018). Prediction of the formability limit using damage mechanics, J. Phys. Conf. Ser., 1063, pp. 012066, DOI: 10.1088/1742-6596/1063/1/012066.

[96] Benallal, A., Billardon, R., Lemaitre, J. (1991). Continuum damage mechanics and local approach to fracture: Numerical procedures, Comput. Methods Appl. Mech. Eng., 92(2), pp. 141-155, DOI: 10.1016/0045-7825(91)90236-Y.

[97] Badreddine, H., Saanouni, K. (2017). On the full coupling of plastic anisotropy and anisotropic ductile damage under finite strains, Int. J. Damage Mech., 26(7), pp. 1080-1123, DOI: 10.1177/1056789516635729.

[98] Badreddine, H., Yue, Z.M., Saanouni, K. (2017). Modeling of the induced plastic anisotropy fully coupled with ductile damage under finite strains, Int. J. Solids Struct., 108, pp. 49-62, DOI: 10.1016/j.ijsolstr.2016.10.028.

[99] McClintock, F.A. (1968). A Criterion for Ductile Fracture by the Growth of Holes, J. Appl. Mech., 35(2), pp. 363, 
DOI: $10.1115 / 1.3601204$

[100] Gurson, A.L. (1977). Continuum Theory of Ductile Rupture by Void Nucleation and Growth: Part I-Yield Criteria and Flow Rules for Porous Ductile Media, J. Eng. Mater. Technol., 99(1), pp. 2, DOI: 10.1115/1.3443401.

[101] Ying, L., Wang, D., Liu, W., Wu, Y., Hu, P. (2018). On the numerical implementation of a shear modified GTN damage model and its application to small punch test, Int. J. Mater. Form., 11(4), pp. 527-539,

DOI: $10.1007 / \mathrm{s} 12289-017-1362-7$.

[102] Zhou, J., Gao, X., Sobotka, J.C., Webler, B.A., Cockeram, B. V. (2014). On the extension of the Gurson-type porous plasticity models for prediction of ductile fracture under shear-dominated conditions, Int. J. Solids Struct., 51(18), pp. 3273-3291, DOI: 10.1016/j.ijsolstr.2014.05.028.

[103] He, Z., Zhu, H., Hu, Y. (2021). An improved shear modified GTN model for ductile fracture of aluminium alloys under different stress states and its parameters identification, Int. J. Mech. Sci., 192, pp. 106081, DOI: $10.1016 /$ j.ijmecsci.2020.106081.

[104] Ohata, M., Fukahori, T., Minami, F. (2010). Damage Model for Predicting the Effect of Steel Properties on Ductile Crack Growth Resistance, Int. J. Damage Mech., 19(4), pp. 441-459, DOI: 10.1177/1056789509103704.

[105] Fukahori, T., Ohata, M., Minami, F., Kayamori, Y., Inoue, T. (2008). Damage Model for Simulating the Effect of Material Properties on Ductile Crack Growth Resistance-Simulation of Ductile Crack Growth-, Tetsu-to-Hagane, 94(6), pp. 222-230, DOI: 10.2355/tetsutohagane.94.222.

[106] Ishiguro, T., Yoshida, Y., Yukawa, N., Ishikawa, T. (2009). Deformation Analysis of Shearing Process Using Results of Notched Round Bar Tension Test, Mater. Trans., 50(7), pp. 1671-1677, DOI: 10.2320/matertrans.MF200903.

[107] Jiang, W., Li, Y., Su, J. (2016). Modified GTN model for a broad range of stress states and application to ductile fracture, Eur. J. Mech. - A/Solids, 57, pp. 132-148, DOI: 10.1016/j.euromechsol.2015.12.009.

[108] Gao, L., Zhao, J., Quan, G., Xiong, W., An, C. (2019). Study on the Evolution of Damage Degradation at Different Temperatures and Strain Rates for Ti-6Al-4V Alloy, High Temp. Mater. Process., 38(2019), pp. 332-341,

DOI: 10.1515/htmp-2018-0091.

[109] Bouchard, P.-O., Bourgeon, L., Fayolle, S., Mocellin, K. (2011). An enhanced Lemaitre model formulation for materials processing damage computation, Int. J. Mater. Form., 4(3), pp. 299-315, DOI: 10.1007/s12289-010-0996-5.

[110] Hammi, Y., Horstemeyer, M.F. (2007). A physically motivated anisotropic tensorial representation of damage with separate functions for void nucleation, growth, and coalescence, Int. J. Plast., 23(10-11), pp. 1641-1678,

DOI: 10.1016/j.ijplas.2007.03.010.

[111] Santaoja, K.J. (2019). On continuum damage mechanics, Raken. Mek., 52(3), pp. 125-147, DOI: $10.23998 / \mathrm{rm} .76025$.

[112] Besson, J., Guillemer-Neel, C. (2003). An extension of the Green and Gurson models to kinematic hardening, Mech. Mater., 35(1-2), pp. 1-18, DOI: 10.1016/S0167-6636(02)00169-2.

[113] Barlat, F., Brem, J.C., Yoon, J.W., Chung, K., Dick, R.E., Lege, D.J., Pourboghrat, F., Choi, S.-H., Chu, E. (2003). Plane stress yield function for aluminum alloy sheets—part 1: theory, Int. J. Plast., 19(9), pp. 1297-1319,

DOI: 10.1016/S0749-6419(02)00019-0.

[114] Cazacu, O. (2018). New yield criteria for isotropic and textured metallic materials, Int. J. Solids Struct., 139-140, pp. 200-210, DOI: 10.1016/j.ijsolstr.2018.01.036.

[115] Cazacu, O., Plunkett, B., Barlat, F. (2006). Orthotropic yield criterion for hexagonal closed packed metals, Int. J. Plast., 22(7), pp. 1171-1194, DOI: 10.1016/j.ijplas.2005.06.001.

[116] Costin, L.S. (1985). Damage mechanics in the post-failure regime, Mech. Mater., 4(2), pp. 149-160, DOI: 10.1016/0167-6636(85)90013-4.

[117] Rabotnov, Y.N. (1969).Creep rupture. Applied Mechanics, Berlin, Heidelberg, Springer Berlin Heidelberg, pp. $342-$ 349.

[118] Wulfinghoff, S., Reese, S. (2015). On Anisotropic Damage Theories based on 2nd Order Damage Tensors, PAMM, 15(1), pp. 165-166, DOI: 10.1002/pamm.201510073.

[119] Voyiadjis, G.Z., Kattan, P.I. (1999).Damage and Plasticity in Metals. Advances in Damage Mechanics: Metals and Metal Matrix Composites, Elsevier, pp. 109-157.

[120] Olsen-Kettle, L. (2019). Bridging the macro to mesoscale: Evaluating the fourth-order anisotropic damage tensor parameters from ultrasonic measurements of an isotropic solid under triaxial stress loading, Int. J. Damage Mech., 28(2), pp. 219-232, DOI: $10.1177 / 1056789518757293$.

[121] Desmorat, R., Desmorat, B., Olive, M., Kolev, B. (2018). Micromechanics based framework with second-order damage tensors, Eur. J. Mech. - A/Solids, 69, pp. 88-98, DOI: 10.1016/j.euromechsol.2017.11.014.

[122] Badreddine, H., Saanouni, K., Nguyen, T.D. (2015). Damage anisotropy and its effect on the plastic anisotropy 
evolution under finite strains, Int. J. Solids Struct., 63, pp. 11-31, DOI: 10.1016/j.ijsolstr.2015.02.009.

[123] Fincato, R., Tsutsumi, S. (2021). Coupled elasto-viscoplastic and damage model accounting for plastic anisotropy and damage evolution dependent on loading conditions, Comput. Methods Appl. Mech. Eng., 387, pp. 114165, DOI: $10.1016 /$ j.cma.2021.114165.

[124] Nagaki, S., Saboi, D., Muroi, K., Iizuka, M., Oshita, K. (2016). Anisotropic Damage Evolution for Perforated Sheet under Tensile Deformation, Key Eng. Mater., 725, pp. 489-494, DOI: 10.4028/www.scientific.net/KEM.725.489.

[125] Shahzamanian, M.M. (2018). Anisotropic Gurson-Tvergaard-Needleman plasticity and damage model for finite element analysis of elastic-plastic problems, Int. J. Numer. Methods Eng., 115(13), pp. 1527-1551,

DOI: $10.1002 /$ nme.5906.

[126] Takazawa, H., Iwamatsu, F., Miyazaki, K., Yamada, H., Ogasawara, N. (2019). Effect of strain rate on crack propagation of ductile fracture behavior using damage mechanics model, Proc. Comput. Mech. Conf., 2019.32, pp. 099, DOI: $10.1299 /$ jsmecmd.2019.32.099.

[127] Tang, B., Li, C., Xiao, G., Zhao, W., Li, H. (2017). Numerical modeling and experimental verification of ductile damage in boron steel hot stamping process, Procedia Eng., 207, pp. 675-680, DOI: 10.1016/j.proeng.2017.10.1040.

[128] Kumar, M., Gautam, S.S., Dixit, P.M. (2019). A non-linear ductile damage growth law at elevated temperature, Sādhanā, 44(6), pp. 145, DOI: 10.1007/s12046-019-1119-8.

[129] Hirose, S., Toi, Y. (2017). Investigation of continuum damage mechanics model without element size sensitivity, Trans. JSME (in Japanese), 83(852), pp. 17-00130-17-00130, DOI: 10.1299/transjsme.17-00130.

[130] Huang, L., Yao, Y. (2021). A thermodynamically nonlocal damage model using a surface-residual-based nonlocal stress, J. Mech., 37, pp. 484-495, DOI: 10.1093/jom/ufab017.

[131] Andrade, F.X.C., César de Sá, J.M.A., Andrade Pires, F.M. (2011). A Ductile Damage Nonlocal Model of Integraltype at Finite Strains: Formulation and Numerical Issues, Int. J. Damage Mech., 20(4), pp. 515-557, DOI: $10.1177 / 1056789510386850$.

[132] Sprave, L., Menzel, A. (2020). A large strain gradient-enhanced ductile damage model: finite element formulation, experiment and parameter identification, Acta Mech., 231(12), pp. 5159-5192, DOI: 10.1007/s00707-020-02786-5.

[133] Brepols, T., Wulfinghoff, S., Reese, S. (2017). Gradient-extended two-surface damage-plasticity: Micromorphic formulation and numerical aspects, Int. J. Plast., 97, pp. 64-106, DOI: 10.1016/j.ijplas.2017.05.010.

[134] Enakoutsa, K. (2014). An improved nonlocal Gurson model for plastic porous solids, with an application to the simulation of ductile rupture tests, Appl. Math. Model., 38(11-12), pp. 2791-2799, DOI: 10.1016/j.apm.2013.11.007.

[135] Cortese, L., Nalli, F., Rossi, M. (2016). A nonlinear model for ductile damage accumulation under multiaxial nonproportional loading conditions, Int. J. Plast., 85, pp. 77-92, DOI: 10.1016/j.ijplas.2016.07.003.

[136] Papasidero, J., Doquet, V., Mohr, D. (2015). Ductile fracture of aluminum 2024-T351 under proportional and nonproportional multi-axial loading: Bao-Wierzbicki results revisited, Int. J. Solids Struct., 69-70, pp. 459-474, DOI: 10.1016/j.ijsolstr.2015.05.006.

[137] Zhang, K., Badreddine, H., Saanouni, K. (2018). Thermomechanical modeling of distortional hardening fully coupled with ductile damage under non-proportional loading paths, Int. J. Solids Struct., 144-145, pp. 123-136, DOI: 10.1016/j.ijsolstr.2018.04.018.

[138] Neves, R.S., Ferreira, G.V., Malcher, L. (2020). Gurson-based incremental damage in fatigue life estimate under proportional and non-proportional loading: Constant amplitude and low cycle regime applications, Theor. Appl. Fract. Mech., 108, pp. 102678, DOI: 10.1016/j.tafmec.2020.102678.

[139] Baltic, S., Asadzadeh, M.Z., Hammer, P., Magnien, J., Gänser, H.-P., Antretter, T., Hammer, R. (2021). Machine learning assisted calibration of a ductile fracture locus model, Mater. Des., 203, pp. 109604, DOI: $10.1016 /$ j.matdes.2021.109604.

[140] Sun, Q., Lu, Y., Chen, J. (2020). Identification of material parameters of a shear modified GTN damage model by small punch test, Int. J. Fract., 222(1-2), pp. 25-35, DOI: 10.1007/s10704-020-00428-4.

[141] Nahshon, K., Hutchinson, J.W. (2008). Modification of the Gurson Model for shear failure, Eur. J. Mech. A/Solids, 27(1), pp. 1-17, DOI: 10.1016/j.euromechsol.2007.08.002. 